\title{
Pathology of the Heart in Friedreich's Ataxia: Review of the Literature and Report of One Case
}

\author{
G. SANCHEZ-CASIS, M. COTE AND A. BARBEAU
}

SUMMARY: $A$ single case of typical Friedreich's ataxia was analyzed for cardiac changes and compared to the findings from the literature. Macroscopically, there was a cardiomegaly with some degree of ventricular hypertrophy and probable mild dilatation of the auricles. The more important and constant histologic changes were myocardial fibrosis and degeneration of the cardiac muscle cells. Granular deposits of calcium salts and iron were found in the muscle cells. A cardiomyopathy hypertrophic in type and occasionally obstructive appears to be an integral part of Friedreich's ataxia.

RESUMÉ: Les modifications cardiaques trouvées dans le coeur d'un cas d'ataxie de Friedreich "typique" préalablement étudié sont analysées et comparées aux données de la littérature. Macroscopiquement, il y avait une cardiomégalie avec un certain degré d'hypertrophie ventriculaire ainsi qu'une probable dilatation légère des auricules. Histologiquement, les changements les plus remarquables et constants étaient une fibrose du myocarde ainsi qu'une dégénérescence des cellules musculaires cardiaques. Des dépôts granuleux de sels de calcium et de fer furent identifiés dans ces cellules musculaires. En conclusion, une cardiomyopathie de type hypertrophique et parfois obstructive semble devoir être une partie intégrale de l'ataxie de Friedreich.

From the Centre Hospitalier Universitaire de Sherbrooke; and the Clinical Research Institute of Montreal.

Reprint requests for the complete supplement on Friedreich's ataxia to Dr. André Barbeau, Clinical Research Institute of Montreal, 110 Pine Avenue west, Montreal, Quebec, Canada H2W IR7.

\section{INTRODUCTION}

Friedreich $(1861,1863)$ described the disease that bears his name. In the autopsy study of three cases, he found "myocardial damage" in two. It was not until 1887 that Pitt, in London, made the clinicopathological correlation in patients with Friedreich's ataxia and heart disease.

In 1905, Lannois and Porrot, and, in 1933, Guizetti described 4 cases of extensive myocardial fibrosis and fatty degeneration and sclerosis of the coronary arteries without obstruction. Nadas et al (1951) found similar changes in one case except for extensive obstruction of coronary arteries. Lorenz and collaborators (1950) described myocardial hypertrophy and dilatation, slight irregularity and calcification of the aortic valve, and granular degeneration and fibrosis of the myocardium with some "small cell" infiltration. In 1952, Schilero et al gave a complete pathological and clinical description of common and uncommon cardiac changes. Common ones were similar to those described above, with the exception of specific round-cell infiltration with lymphocytes and eosinophils. The uncommon ones were pericardial effusion, complete heart block or bundlebranch book, infiltration with mast cells, epicardial petechiae and hemorrhages, and fibrous pericardial thickening.

Hartman (1960) proposed a possible pathogenic mechanism. The myocardial changes could be the result of sympathetic overactivity secondary to medullary lesions of the vagal nuclei. However, Thilenius and Grossman (1961) noted the his- tological differences between the central nervous system and myocardial lesions. In 1962, Boyer et al reported 33 autopsy cases: $55 \%$ had myocardial alterations. The authors presented several theories about the pathogenesis. They stressed the possible role of scoliosis, a "neurogenic factor", rheumatic fever, a congenital malformation, coronary artery occlusion or narrowing, and finally a single inborn error of metabolism expressing itself in both the central nervous system and the myocardium.

The same year, James and Fisch (1963) in one autopsy found a cardiomegaly and presented a complete study of the gross and microscopic findings. Many of these were similar to the ones described before, and others were non-specific. Among the findings of this report were the thorough study of coronary arteries and the changes in the other organs. However, many of these changes were not specific enough for a differential diagnosis from other pathologic entities. Finally, in the discussion, James and Fisch raised the possibility that involvement of the small arteries is responsible for the "myocarditis" in Friedreich's ataxia.

In 1964, Ivemark and Thoren noted in three autopsy cases, subintimal fibrosis of the large and medium-size branches of the coronary arteries and subendocardial fibroelastosis. They suggested an infectious or toxic etiology. In 1965, Soulié and collaborators reviewed 25 autopsy cases. The more important myocardial changes were the diffuse fibrosis and thickening of the media of the arterioles with microthrombi. In their own case, they described 
1973

$$
\text { R.B. 13-M A B-23 }
$$
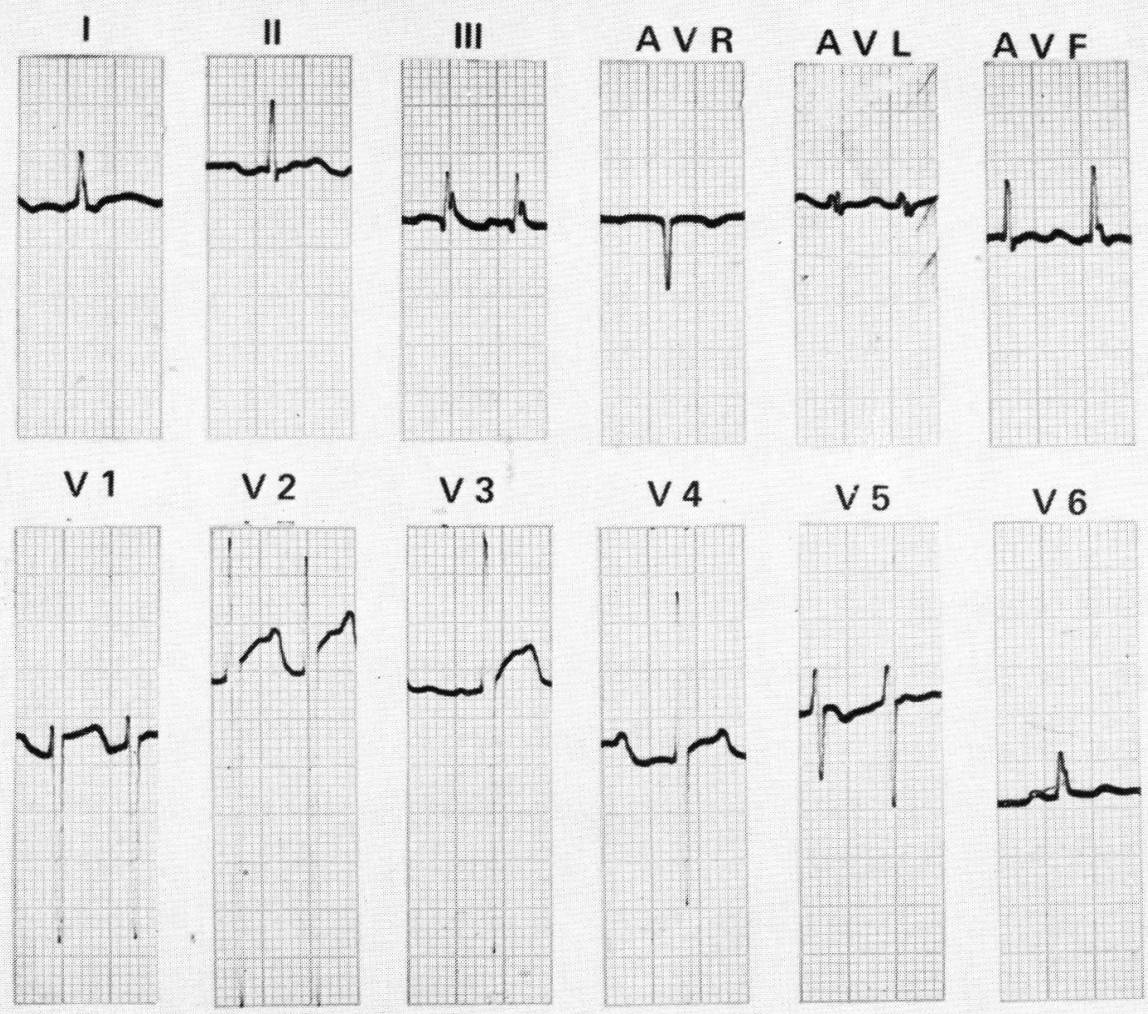

V 6

Figure 1-Electrocardiogram two years prior to necropsy study showing atrial fibrillation with rapid ventricular rate and non-specific ST-T changes.

almost the same changes as in the literature.

Chelius et al, in 1967, studied a family of 4 afflicted siblings; three had clinically manifest heart involvement, and 2 developed diabetes mellitus prior to death. The autopsy in 3 siblings showed cardiac changes similar to those previously described.

Hewer (1968) showed that over $50 \%$ of 82 patients died of cardiac complications, while nearly $75 \%$ had evidence of cardiac involvement during life. In 1970, Boehm et al described a case with hypertrophic subaortic stenosis. The microscopic alterations were again similar to the cases in the literature. Elias et al, in 1972, reported another case with hypertrophic subaortic stenosis. The same year, Tanaka et al (1972) described a case with extensive myocardial fibrosis and no changes in the spinal cord. Gach and coauthors (1971) published a case with hypertrophic obstructive cardiomyopathy involving both ventricles.

In 1972, Olsen described the autopsy findings in 3 cases, and Krongrad and Joos (1972), an additional case of a 7 year old girl who had a paternal history of early death secondary to myocardial infarction. They reported for the first time an elevation of the LDH isoenzyme-5 in a case of Friedreich's ataxia. Finally, they stressed coronary artery disease and small-vessel occlusion as possible etiological factors and their relationship to the hyperlipidemias and diabetes, both familial disorders producing early diffuse coronary artery disease.

Ruschhaupt et al (1972) described another case associated with idiopathic hypertrophic subaortic stenosis and also stressed this kind of association, both disorders having a familial incidence. The same year, Harris and Nghiem (1972) published an extensive study of cardiomyopathies and included the cardiomyopathies associated with generalized neurological or muscular diseases. They gave a thorough description of the histopathology, especially the fibrosis of the conduction system and sino-atrial node. Finally, one of the more recent articles from Gabriel et al (1974) stated that in the majority of cases the cardiopathy of Friedreich's ataxia belongs to the non-obstructive hypertrophic cardiomyopathies.

\section{CASE REPORT (RB-13-MAB-23)}

A 28 year old male Caucasian was admitted at another hospital for abdominal and chest pains. He died 2 weeks later of renal failure. Only the heart, a few days after embalming, was available for the present necropsy studies. The first symptoms of Friedreich's ataxia appeared at the age of 10 . The neurological impairment progressed rapidly, and he had been confined to a wheel-chair since the age of 19. Two other siblings in this family of 9 children also suffered from Friedreich's ataxia.

Two years prior to his death, he was examined by one of us (M.C.). $\mathrm{He}$ presented few cardiovascular symptoms. He complained of slight shortness of breath after meals, although he was comfortable in the recumbent position. There was no

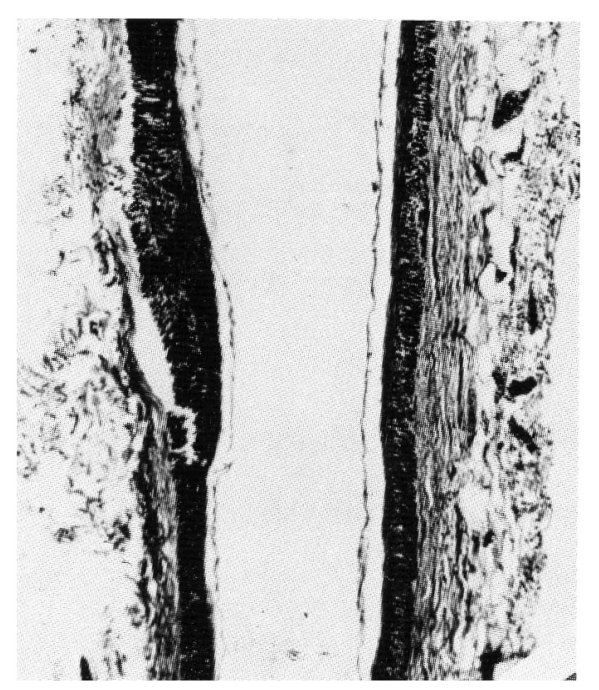

Figure 2-Artery of the atrioventricular node without pathologic changes. (X63) 


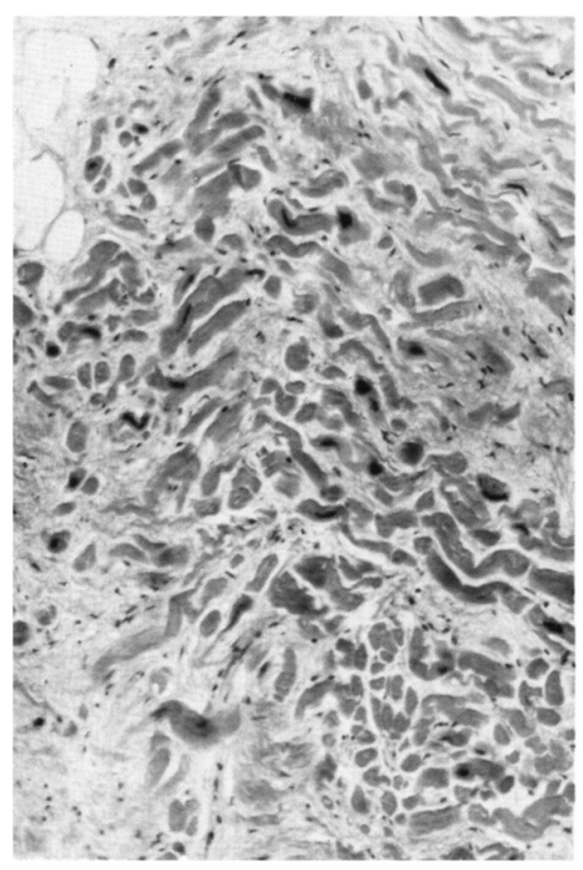

Figure 3-Part of the atrioventricular nodes with few small areas of fibrosis. (X160)

Figure 4-A ganglion cell with granular degeneration in the epicardial fat, close to the sino-atrial node. (X160)

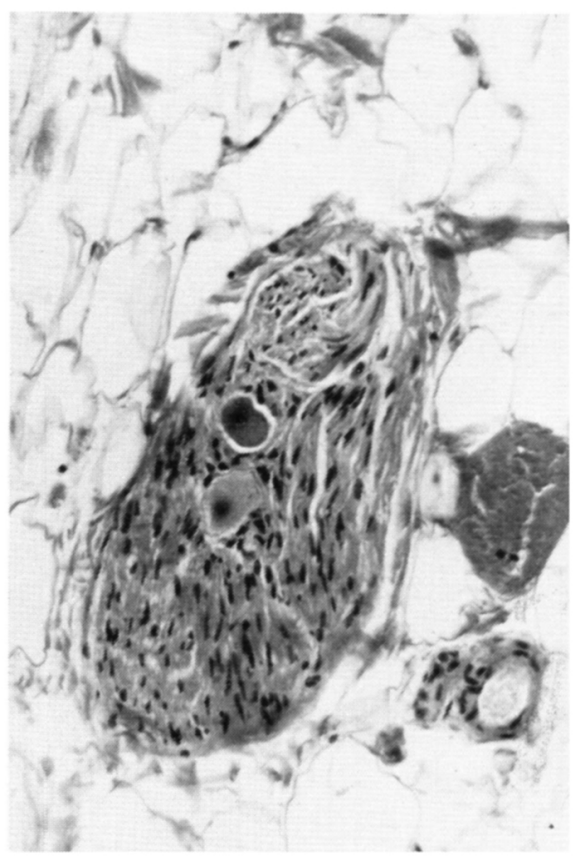

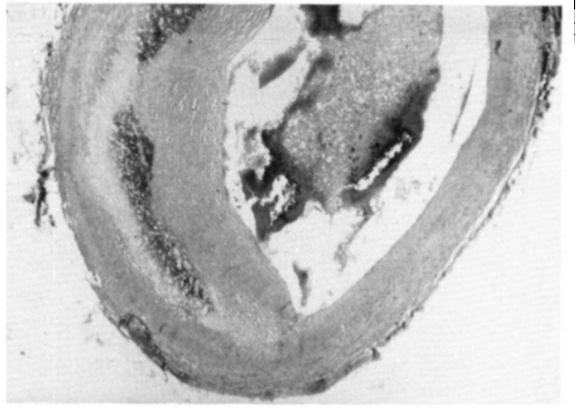

Figure 5-Microphotograph of a cross section of the anterior descending coronary artery to show intima thickening and an atheromatous plaque to the left. (X25)

history of frequent respiratory infections. He had experienced episodes of palpitations in the previous two years and had been digitalized intermittently. On physical examination, he was non-cyanotic, slightly dyspneic, and moderately obese. B.P. 120/80. Heart rate irregular $110 /$ min. There was no jugular venous distension. The lungs were clear to auscultation. The chest was deformed by a 60 degree dorsal scoliosis. Cardiac examination and auscultation revealed a slightly hyperactive right ventricle, and increased second pulmonic sound, and a protodiastolic third heart sound. No murmurs were heard. The electrocardiogram (Figure 1) showed atrial fibrillation with a rapid ventricular rate of 120 per minute, QRS axis of $+60^{\circ}$ and non-specific ST-T changes. Cardiac catheterization revealed the following pressures: right atrium $6 \mathrm{~mm} \mathrm{Hg}$ (mean), right ventricle $24 / 4 \mathrm{~mm} \mathrm{Hg}$, pulmonary artery $26 / 10$, left ventricle $107 / 12 \mathrm{~mm} \mathrm{Hg}$, and aorta $108 / 92 \mathrm{~mm} \mathrm{Hg}$. There was no significant intraventricular systolic pressure gradient at rest. The left ventricular and diastolic pressure was at the upper limit of normal. The cardiac index was decreased at $1.341 / \mathrm{min} . / \mathrm{m}^{2}$. The left ventricular angiogram revealed a diffusely hypokinetic and hypertrophied left ventricle with an ejection fraction of $49 \%$. Myocardial metabolic studies were normal with no lactate production at rest and normal oxygen extraction. The oxyhemoglobin dissociation curve was

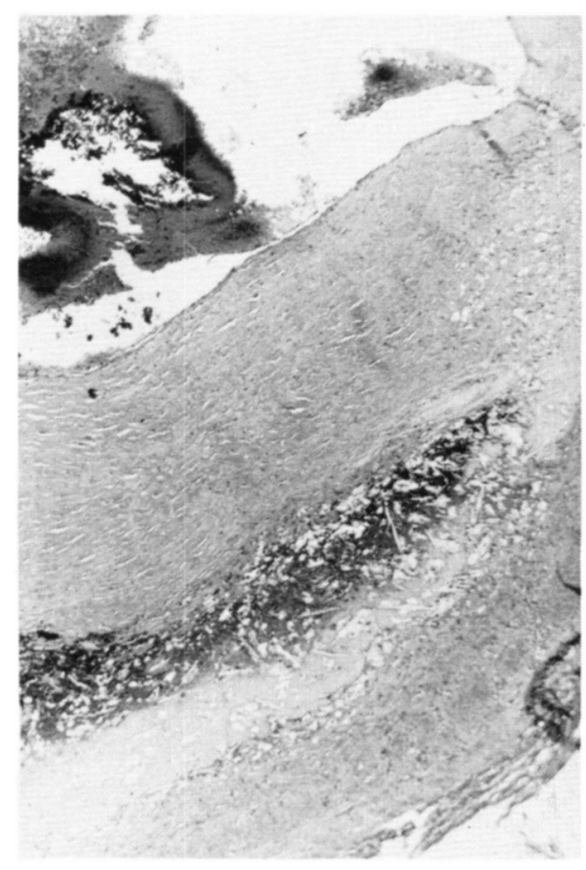

Figure 6-High-power view of the artery to show the focal proliferation and sclerosis of the intima and the atheromatous plaque. (X160)

Figure 7-Median artery branch with no pathologic changes. (X63)

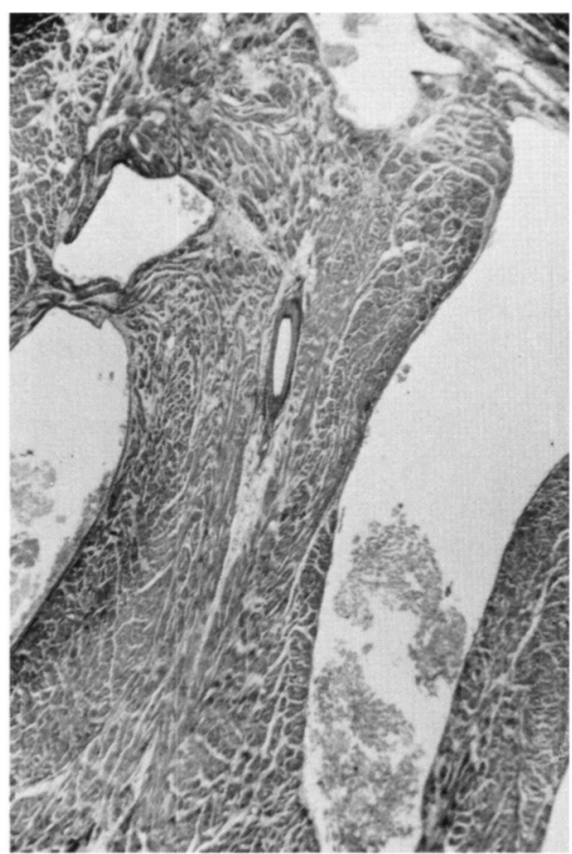




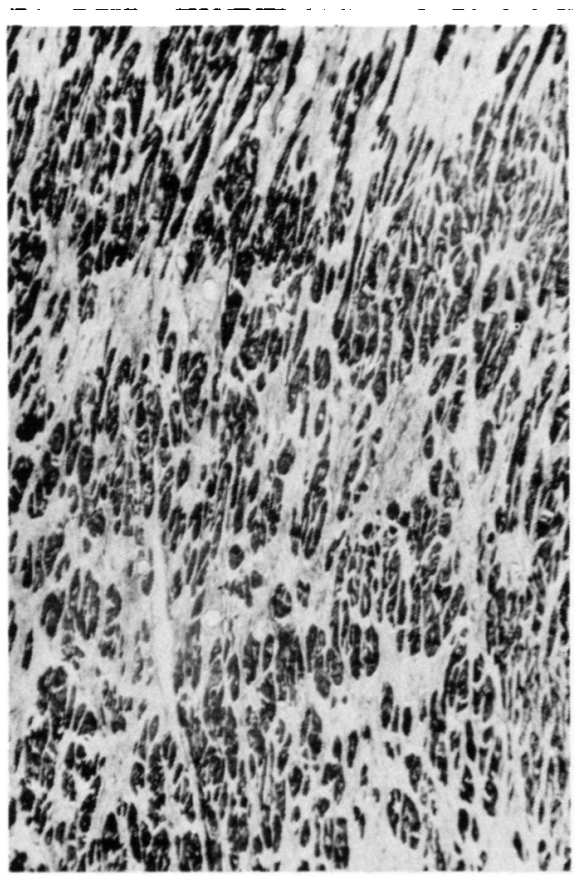

Figure 8-Part of the areas of myocardial fibrosis. Also, there are some small arteries without pathologic changes. (X25)

normal. The patient was digitalized, and small doses of propanolol had to be added to maintain a controlled ventricular rate. The clinical and hemodynamic findings were compatible with a non-obstructive hypertrophic cardiomyopathy. This patient was hospitalized 3 months before his death for the metabolic studies included in the protocol. Cardiac status was essentially the same as reported above.

\section{Necropsy findings}

Only the heart, previously embalmed, was available for these studies. For this reason, some of the pathologic changes were interpreted in relation to the artifacts produced by that procedure. The neuropathology of the same patient will be reported in detail later. It showed the classical findings of Friedreich's ataxia with degeneration of the posterior roots, ganglia and dorsal columns, of the spinocerebellar pathways and the pyramidal tracts. The gross pathology showed a cardiomegaly of $600 \mathrm{gm}$. with normal distribution of epicardial fat. The shape of the left ventricle was spherical. The left and right auricles were dilated and there was a mild hypertrophy of both ventricles with decreased capacity of the left ventricle. The different measures were: pulmonary valve $6.0 \mathrm{~cm}$., tricuspid valve $11.0 \mathrm{~cm}$., aortic valve $6.0 \mathrm{~cm}$., mitral valve $7.0 \mathrm{~cm}$., left ventricle wall thickness $1.8 \mathrm{~cm}$., and right ventricle $0.6 \mathrm{~cm}$. The endocardium, myocardium, and epicardium were difficult to evaluate because of embalming changes. However, there were areas of whitish discoloration and congestion in the myocardium. Macroscopically, the coronary arteries had a normal architecture with a normal distribution.

The arteries of the atrioventricular (Figure 2) and sino-atrial node were dissected, and none showed microscopic changes. Sections of the atrioventricular node showed only mild fibrosis, mild nuclear changes, and some inflammatory cells (Figure 3). Sections of the sino-atrial node were normal. A group of ganglion cells and a nerve were found in the fatty tissue surrounding the sinus node. One of the ganglion cells showed granular degeneration, which could have been a postmortem change (Figure 4). The rest of the conduction system showed no significant pathologic changes.

Figure 9-Infiltration of mononuclear cells, mainly lymphocytes. (X63)

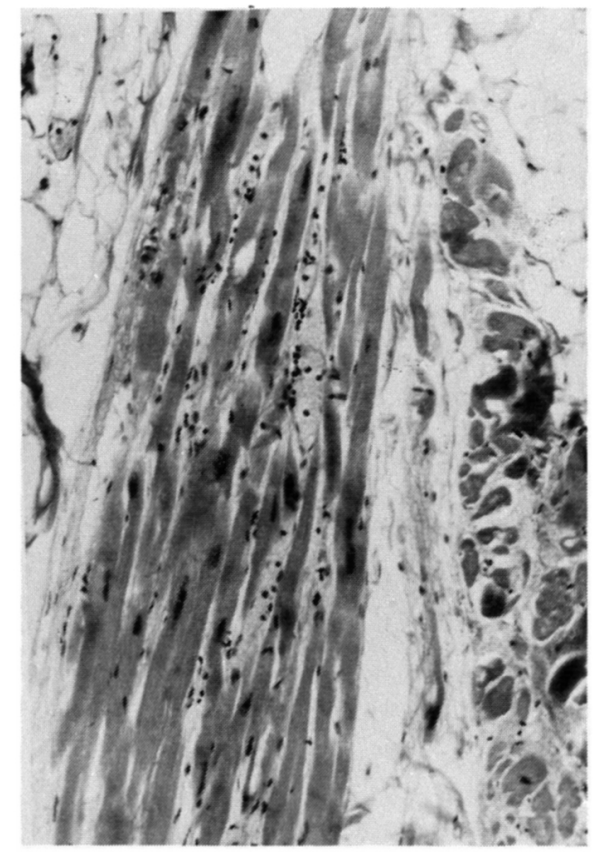

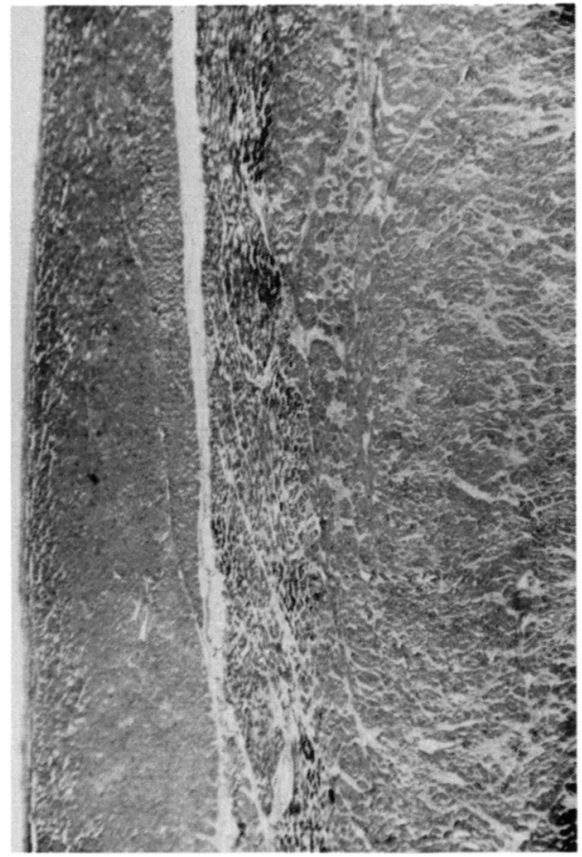

Figure 10-Zone of degeneration with focal areas of calcification. (X63)

Generally, the coronary arteries showed few morphological changes, except for some focal proliferation of the intima, especially at the level of an atheromatous plaque (Figures 5 and 6). Microscopic examination of medium and small branches of the coronary arteries revealed no significant pathological changes (Figure 7).

Evidence of myocardial damage was diffuse and severe with intercellular fibrosis of irregular distribution affecting practically the whole cardiac muscle more pronounced in the left ventricle and septum (Figure 8).

Other changes, previously described, were also found such as infiltration by some lymphocytes and monocytic cells of the interstitium and the zones of fibrosis (Figure 9). The only unusual findings were zones of cardiac muscle degeneration with calcification that were well demonstrated with the Von Kossa stain (for calcium) (Figures 10,11 and 12). However, Prussianblue stains also showed the presence of iron pigment mixed in with the calcium. These zones of calcification were localized in the septum close to the conduction system (bundle of His). 


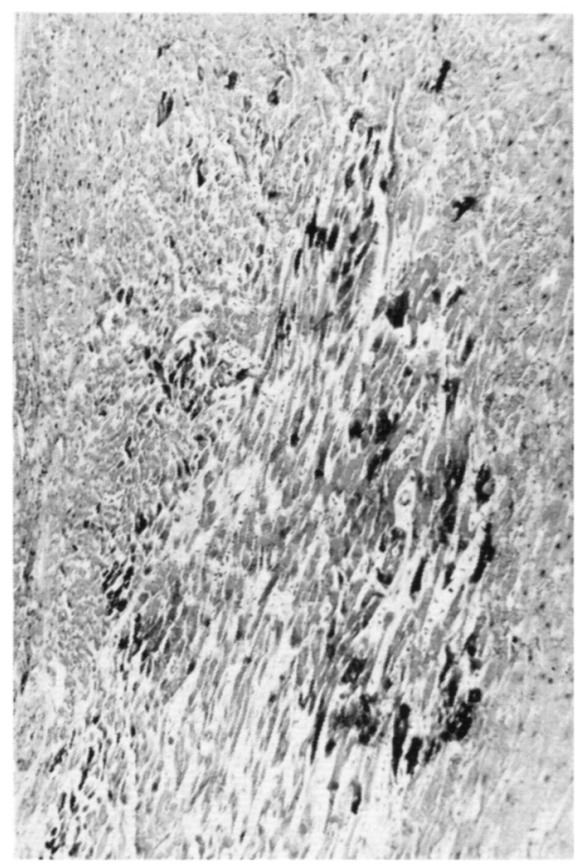

Figure $1 /$-High power of one of the areas of fibrosis, degeneration, and calcification. The special stain for iron was also positive. (X160)

Figure 12-Other high power to show the granular aspect and the intracellular deposits of calcium. (X160)

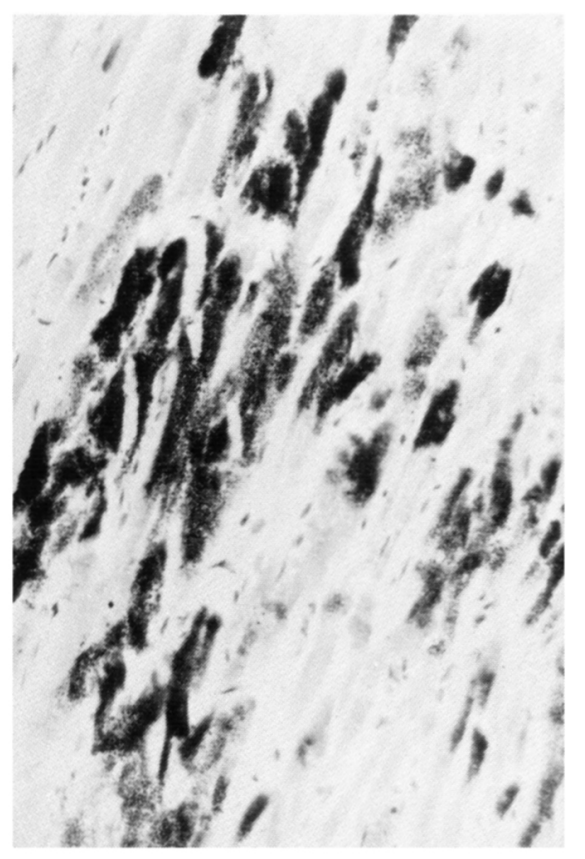

\section{DISCUSSION}

After reviewing the literature, the more specific changes macroscopically were a cardiomegaly with some degree of ventricular hypertrophy and probable mild dilatation of the auricles.

Regarding the histologic changes, the more important and constant ones were myocardial fibrosis and degeneration of the cardiac muscle cells. The sclerotic changes of the coronary arteries and their branches, we believe, were nonspecific. The changes were more degenerative, and, as in our case, there were atheromatous plaques involving mainly the major branches of the coronary arteries, suggesting secondary myocardial damage and lending support to the hypothesis that the primary disease might predispose to early atherosclerosis. The distribution and severity of the myocardial fibrosis and morphological changes are similar to previously described cases, being diffuse, but more preponderant in the anterior wall of the left ventricle and septum.

The involvement of the septum atroventricular node, close to the His bundle and bundle branches, might explain in part the frequent abnormalities of the electrocardiograms and vectocardiograms, such as QRS-axis deviation and right and left ventricular hypertrophy patterns. The conduction system does not, however, appear to be selectively involved.

The only findings not previously described in the literature are the granular deposits of calcium salts and iron in the muscle cells. Most likely, this is a dystrophic metabolic change secondary to cellular degeneration and fibrosis, but its primary relationship to the disease cannot be ruled out. In idiopathic hypertrophic subaortic stenosis (IHSS) myocardial hypertrophy, similar morphological evidence of myocardial damage has been found. The disorderly arrangement of short muscle fibers characterizing this cardiomyopathy has not been found in this case or previously reported cases of Friedreich's ataxia.

In conclusion, a cardiomyopathy, hypertrophic in type and occasionally obstructive appears to be an integral part of Friedreich's ataxia. We think the pathological changes of the coronary vasculature can explain only in part the diffuse myócardial damage and hypertrophy. The most appealing hypothesis remains an unidentified genetically inherited inborn error, or errors, of metabolism as the etiology of the multiple system involvement in Friedreich's ataxia.

\section{ACKNOWLEDGMENTS}

We express our gratitude to Dr. Sterling Carpenter of the Montreal Neurological Institute for having helped in making material available.

\section{REFERENCES}

BOEHM, T. M., DICKERSON, R. B. and GLASSER, S. P. (1970). Hypertrophic subaortic stenosis occurring in a patient with Friedreich's ataxia. Amer. J. Med. Sci., 260, 279-284.

BOYER, S. H., CHISHOLM, A. W. and McK USICK, V. A. (1962). Cardiac aspect of Friedreich's ataxia. Circulation, 25, 493-505.

CHELIUS, C. V., RESNICK, J. and LATORRACA, R. (1967). Myocardiopathy and other associated non-neurological manifestations in Friedreich's ataxia. Wisconsin Med. J., 66, 427-434.

ELIAS, G., GUERIN, R., SPITAELS, S., FOURON, S. C. and DAVIGNON, A. (1972). Sténose musculaire sous-aortique et ataxie de Friedreich. Union Méd. Can. 101, 474-478.

FRIEDREICH, N. (1863). Über degenerative atrophie der spinalen hinterstränge. Virchows Arch. Path. Anat., 26, 391-419 and 433-459.

GABRIEL, B., PINSARD, N., GERARD, R. and LOUCHET, E. (1974). Association d'une cardiomyopathie et d'une dégénérescence spino-cérébelleuse. (Maladie de Friedreich). A propos d'une observation. Pédiatrie, 29, 367-377.

GACH, J. V., AUDRIANGE, $M$. and FRANCK, G. (1971). Hypertrophic obstructive cardiomyopathy and Friedreich's ataxia: Report of a case and review of literature. Amer. J. Cardiol., 27, 436-441.

GUIZZETTI, P. (1933). Per la conoscenza della miocardite dell'atassia di Friedreich. Riv. di Pat. Nerve. Mentali, 41, 545.

HARRIS, L. D. and NGHIEM, Q. (1972). Cardiomyopathies in infants and children. Prog. Cardiovasc. Dis., 15, 225-286.

HARTMAN, J. M. and BOOTH, R. W. (1960). Friedreich's ataxia: A neurocardiac disease. Am. Heart J., 60, 716-720.

HEWER, R. L. (1968). Study of Fatal cases in Friedreich's ataxia. Brit. Heart J., 31, 3-41. 
IVEMARK, B, and THOREN, C. (1964). The pathology of heart in Friedreich's ataxia - Changes in coronary arteries and myocardium. Acta Med. Scand., 175, 227-237.

JAMES, T. N. and FISCH, C. (1963). Observations on the cardiovascular involvement in Friedreich's ataxia. Amer. Heart J., 66, 164-175.

KRONGRAD, E. and JOOS, H. A. (1972). Friedreich's ataxia in childhood: Case report with possible myocardial infarction, cerebrovascular thromboembolization and persistent elevation of cardiac specific LDH. Chest, 61, 644-648.

LANNOIS, M. and PORRO'T, A. (1905). Le coeur dans la maladie de Friedreich. Rev. de Méd., 25, 853.

LORENZ, T. H., KURTZ, C. M. and SHAPIRO, H. H. (1950). Cardiopathy in
Friedreich's ataxia (spinal form of hereditary sclerosis). Review of literature and analysis of cases in five siblings. Arch. Int. Med. (Chicago), 86, 412-426.

NADAS, A. S., ALIMURUNG, M. M. and SIERACKI, L. A. (1951). Cardiac manifestations of Friedreich's ataxia. New Engl. J. Med., 244, 239-244.

OLSEN, E. G. (1972). Cardiomyopathies. Cardiovasc. Clin., 4, 239-251.

PITT, G. N. (1887). One case of Friedreich's disease: Its clinical history and postmortem appearances. Guy's Hospital Rep., 44, 369-394.

RUSCHHAUPT, D. G., THILENIUS, O. G. and GASSELS, D. E. (1972). Friedreich's ataxia associated with idiopathic hypertrophic subaortic stenosis. Amer. Heart J., 84, 95-102.
RUSSELL, D. S. (1946). Myocarditis in Friedreich's ataxia. J. Path. \& Bact., 58, 739-748.

SCHILERO, A. J., ANTZIS, E. and DUNN, J. (1952). Friedreich's ataxia and its cardiac manifestations. Amer. Heart J., 44, 805-822.

SOULIE, P., VERNANT, T., COLONNA, D. and GRYNBERG, J. C. (1965). Aspects cardiaques de la maladie de Friedreich. Coeur Méd. Int., 4, 311-319.

TANAKA, H., NIIMURA, T., KASHIMA, T., et al. (1972). Cardiomyopathy with hereditary cerebellar ataxia. Report of an autopsied case. Jap. Heart J., 13, 369-377.

THILENIUS, O. G. and GROSSMAN, B. J. (1961). Friedreich's ataxia with heart disease in children. Pediatrics, 27, 493-505. 